\title{
Rechazar, omitir y recuperar. Después de... (Cecilia Bartolomé y José J. Bartolomé, 1981)
}

\author{
Baztertu, omititu eta berreskuratu. Después de... \\ (Cecilia Bartolomé y José J. Bartolomé, 1981)
}

\section{Reject, ignore and recover. Después de... (Cecilia Bartolomé y José J. Bartolomé, 1981)}

\section{Juan Caravaca Mompeán ${ }^{1}$}

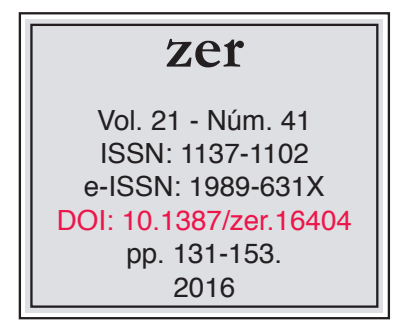

Recibido el 30 de diciembre de 2015, aceptado el 7 de junio de 2016.

\section{Resumen}

El documental Después de... (Cecilia Bartolomé y José J. Bartolomé, 1981), realizado en pleno proceso de transición hacia la democracia en España y fuertemente crítico con su tiempo presente, ha sufrido variaciones en la percepción de su mensaje desde su estreno hasta la actualidad. Este artículo realiza un repaso por las diferentes miradas que se han impuesto sobre su metraje y explica el significado de esta obra para nuestro presente.

Palabras clave: Documental, transición, cine español, historia del cine.

\section{Laburpena}

Después de... (Cecilia Bartolomé eta José J. Bartolomé, 1981) dokumentala Espainiako demokraziaranzko trantsizio-prozesu bete-betean egin zen, eta gogor kritikatu zuen une hura. Dokumentalaren mezua jasotzeko pertzepzioa, ordea, aldatu egin da estreinatu zenetik gaur egun arte. Artikulu honek metrajearen gainean jarri diren begiraden azterketa bat egiten du, eta obra honek gaur egun guretzat duen esanahia azaltzen du.

Gako-hitzak: Dokumentala, trantsizioa, espainiar zinema, zinemaren historia.

\section{Abstract}

The documentary Después de... (Cecilia Bartolomé y José J. Bartolomé, 1981), a movie filmed during the Spanish Transition to democracy who was strongly critical with his present,

\footnotetext{
Universidad Rey Juan Carlos, juancaravacamompean@gmail.com
} 
has undergone changes in the perception of its message since its release to the present. This paper makes a review about its different meanings and explains what it means to our present. Keywords: Documentary, spanish cinema, transition, film history. 


\section{Introducción}

El presente tex to está dedicado a la película Después de ..., realizada por Cecilia Bartolomé y José J. Bartolomé, y a la recepción que ha tenido dicha obra. En esta breve introducción vamos a plantear algunos aspectos generales sobre su producción, distribución y temática así como sobre su papel dentro de la Historia del Cine Español. Nuestro objetivo es hacer una breve presentación para posteriormente establecer una metodología de trabajo con la que estudiar esta película.

La producción de este film, iniciada en abril de 1979 y finalizada en febrero de $1981^{2}$, dio lugar a un largometraje documental con una duración superior a las tres horas que fue dividido en dos películas: No se os puede dejar solos y Atado y bien $a^{a} a d o^{3}$. La duración final de cada una de ellas es de 90 y 99 minutos respectivamente, y su estreno oficial se realizó, dentro de la sección Nuevos Realizadores, en la XXIX edición del Festival de San Sebastián, el 26 de septiembre de 1981. Un mes después, el 15 de octubre, se proyectó en la Setmana de Cinema de Barcelona donde obtuvo el reconocimiento al mejor documental.

A pesar de que había sido presentada en 1981, Después de... no se estrenó en salas comerciales hasta el 7 de noviembre de 1983 debido a un problema con la Dirección General de Cine. Este organismo se negó a concederle la subvención que le correspondía, alegando que más del cincuenta por ciento del metraje contenía imágenes de archivo o de encuestas y reportajes ${ }^{4}$, y los realizadores tuvieron que esperar hasta febrero de 1983 para que esta resolución fuese revocada. Una vez solucionado este inconveniente pudieron recibir "la subvención que le [correspondía] con cargo al Fondo de Protección a la Cinematografía" , optar a los premios de especial calidad y de nuevos realizadores y ser estrenada comercialmente.

En lo relativo a su contenido, el film es un documental compuesto a través de entrevistas y testimonios que buscan registrar las reacciones de los ciudadanos españoles ante el proceso de cambio político que vivía España desde mediados de los años setenta -Transición- $-^{6}$. Este planteamiento está inspirado en la experiencia que vivió José J. Bartolomé durante su trabajo en la película La batalla de Chile (Patricio Guzmán, 1975). La obra del director chileno motivo a los realizadores a lanzarse y "captar lo que no nos estaban contando los informativos" (Gregori, 2009: 958)7. Junto a esta idea inicial, Después de... también incluye intervenciones de líderes políticos y sindicales que dibujan un abanico de opiniones más amplio.

2 La película fue enviada al Ministerio de Cultura para su calificación en esa fecha pero las imágenes que aparecen en ella fueron tomadas, como explica el rótulo que da inicio a la obra, entre Abril de 1979 y finales de 1980. Igualmente, al final de la segunda parte se especifica que el documental fue finalizado en enero de 1981.

3 La versión inicial tenía un montaje de cuatro horas y el título previsto para toda la obra era Después de Franco.

4 Bedoya, J. G. "Después de... documental sobre la Transición Española, ha sido desposeído de las subvenciones estatales". El País, 7 de mayo de 1985, p. 35.

5 Anónimo. "El proceso de Burgos" y "Después de...", rehabilitadas". $A B C, 16$ de febrero de 1983, p. 61.

6 También, como afirmaron los hermanos Bartolomé en una entrevista a Contracampo, el film quería preguntarse por el desencanto de la sociedad española tras la muerte de Franco y por la ilusión que habían despertado las primeras elecciones democráticas de 1977.

7 Bernardo Menz, sonidista en La batalla de Chile, les acompañó durante la filmación. 
Durante los años en los que se filmó, el cine español se encontraba en proceso de adaptación a la nueva legislación promovida por el primer gobierno democrático, el gobierno de UCD. El 11 de noviembre de 1977 el ejecutivo de Adolfo Suárez puso en marcha el Real Decreto 3071/1977 implantando una serie de medidas importantes: el fin de la censura, la eliminación del permiso de rodaje, la instauración de la subvención automática del 15\%, la división de las salas, la obligación de exhibir películas españolas 120 días al año, etc. Esta legislación fue ampliada y modificada en función de la situación política hasta la llegada del primer gobierno socialista. Con este nuevo marco legal, el cine español empezó a construir una imagen de sí mismo que se alejó de la estética a la que se había visto obligado a acogerse durante el franquismo. La Guerra Civil comenzó a ser un tema estrella y los espectadores pudieron ver en pantalla multitud de puntos de vista alejados de la anterior visión única (Caparrós, 1992: 387). En números, los resultados de este periodo arrojan diferentes conclusiones: crecieron los costes de producción, aumentó la deuda acumulada por los fondos de protección, se incrementaron el número de producciones anuales -gracias al desarrollo de las películas $\mathrm{S}$ - y el público empezó a desalojar las salas en las que se proyectaba cine español (Torreiro, 1995: 371-372).

Esos números también afectaron al género en el que se inscribe Después de... El documental siguió siendo minoritario y detrás de él estaban, en su mayoría, personajes que procedían del ámbito marginal del cine franquista o directores que veían en él un acceso más asequible al cine. No obstante, y debido al gran número de producciones, sigue siendo, para el género, "una indudable edad oro" (Riambau, 2001: 126) en comparación con años pasados y futuros. Después de... se inscribe en esta tesitura de cambio y en este novedoso interés por el cine documental. Los realizadores salieron a la calle mostrando una "voluntad de aprehensión de la realidad política inmediata" (Hernández Ruíz \& Pérez Rubio, 2004: 121) para construir un documental que introdujese una nueva opinión sobre la realidad política española.

\section{Objetivo y metodología}

El acercamiento que vamos a realizar a Después de... está inspirado en el texto que Josep M. Català (2010) escribió sobre el trabajo de Jonas Mekas. Este acercamiento al director lituano está publicado dentro de la obra colectiva La casa abierta: el cine doméstico y sus reciclajes contemporáneos (Cuevas, 2010) y en él se reflexiona sobre la aportación de Mekas al cine desde un punto de vista actual.

Català plantea que al analizar el trabajo de Mekas desde unos parámetros modernos, es decir, desde la era digital, donde el formato doméstico no es un planteamiento estético vanguardista como lo fue en las décadas de los sesenta y setenta, su obra pierde valor. Su aportación al cine sería poco relevante dentro de un contexto audiovisual que admite cualquier tipo de manifestación. Al comparar importantes films como Walden: Diaries, Notes and Sketches (1969), Reminiscences of a Journey to Lithuania (1972) o Lost, Lost, Lost (1976) con obras que parten de las mismas premisas formales pero realizadas en esta era digital, la aportación de Mekas quedaría en un segundo plano. De esta forma, el director lituano podría ser definido como un pionero en la introducción y el uso artístico y estético del material doméstico pero su cine habría perdido el valor artístico. 
Las ideas que plantea Català están estrechamente vinculadas con la percepción y la recepción que una obra cinematográfica tiene en su momento presente -el contexto sociocultural e histórico de la recepción- y con el valor que adquiere el film con el paso del tiempo. Es decir, se enmarca dentro de aquellos estudios que tienen en cuentan las condiciones históricas, sociales y culturales con las que un espectador se enfrenta a una obra cinematográfica, y que reflexionan sobre la necesidad de evitar conferirle a una película un significado -buscado o no- y un valor permanente e inalterable con el paso del tiempo (Hernández-Santaolalla, 2010).

Esta corriente de interpretación -estudios de recepción-es, a nuestro juicio, fundamental para el correcto estudio de la Historia del Cine. Compartimos las palabras de Javier Herrera en su investigación acerca de la recepción crítica de Las Hurdes (Luis Buñuel, 1932) cuando afirma que una película solo existe en tanto que es capaz de producir miradas sobre ella y "alcanza su verdadera entidad ontológica, su auténtica existencia o razón de ser en la contemplación por parte del espectador en el propio momento histórico en el que es producida y para el público a quien en principio va destinada" (Herrera, 2001: 399). Es decir, que alcanza su valor dentro de lo que Herrera denomina mirada coetánea. Para nosotros, a esa mirada se debe sumar, irrenunciablemente, la sucesiva serie de miradas que en los diferentes tiempos y lugares han diseñado, otra vez en palabras de Herrera (2001: 400), la "memoria" subjetiva, única, del film.

Bajo esta premisa queremos estudiar el trabajo de los hermanos Bartolomé. Pero, ¿Por qué Después de... es un objeto relevante? En primer lugar, por los problemas políticos y burocráticos que hemos mencionado en la introducción; en segundo lugar, porque hablaba sobre una realidad social inmediata, es decir, era un cine del presente que, inevitablemente, iba a plantear, conforme avanzase la historia, la validez en el tiempo de esta propuesta; en tercer lugar, porque el extenso metraje obligó a dividir el film en dos partes afectando a su exhibición y distribución; en cuarto lugar, porque uno de los directores era una mujer; y, en último lugar, porque se escogió la fórmula documental para lanzar su discurso. Todos estos aspectos hacen que el film sea una pieza especialmente particular dentro de su marco histórico.

Haciendo hincapié en dos de esos hechos -actualidad política y documentaldebemos tener en cuenta que el discurso documental de los hermanos Bartolomé, siguiendo a Bill Nichols, se integra dentro de la modalidad interactiva. Es decir, dentro de aquellos documentales que hacen "hincapié en las imágenes de testimonio o intercambio verbal y en las imágenes de demostración” (Nichols, 1997: 79) trasladando la autoridad textual a los actores sociales reclutados. ¿Por qué esto es relevante? Porque la temática de la película, que pretendía dejar hablar a los españoles sobre los importantes cambios políticos que se estaban sucediendo en la Transición, utiliza, a nuestro juicio, una estrategia discursiva para hacer pasar al texto por historia y que, como comenta Nichols, afecta al espectador porque este "tiene la esperanza de ser testigo del mundo histórico a través de la representación de una persona que habita en él y que hace de ese proceso de habitación una dimensión característica del texto" (Nichols, 1997: 92).

Todas estas particularidades construyeron un determinado horizonte de expectativas que afectó a la recepción de la película durante su tiempo presente y a la posterior interpretación que ha tenido dentro de los estudios fílmicos dedicados a 
investigar sobre la Historia del Cine Español. Investigaciones en las que vemos un creciente interés por el film de los hermanos Bartolomé y un cambio en la percepción de la obra; tal y como expuso brevemente Alejandro Montiel en su trabajo sobre la revista Contracampo en el que aludía a un olvido y desdén inicial hacia el film que terminó transformándose en una recuperación y reivindicación de la película como una obra a considerar dentro de la Historia del Cine Español (Montiel, 2005).

Por tanto, queremos responder a dos preguntas: ¿Qué significa Después de... para nuestro tiempo presente? y ¿Es una propuesta vigente a pesar de haber sido compuesta como un cine del presente? Contestaremos a ellas mirando el film desde tres vertientes. El primero se acercará a los textos que la prensa escribió sobre el film -nos referimos a las noticias relativas a su producción, distribución y estreno y a las críticas cinematográficas recibidas tras su proyección en salas- con el objetivo de construir su mirada coetánea. El segundo buscará la presencia que el film ha tenido en los estudios fílmicos y las sucesivas interpretaciones que se le han adherido. Y finalmente expondremos la que, a nuestro juicio, es la visión que sobre Después de... se impone en la actualidad.

\section{Después de... y sus coetáneos}

En una primera toma de contacto con la prensa, en septiembre de 1979, los hermanos Bartolomé aclararon que la "película-testimonio"8 que estaban filmando debía explicar el cambio político y sociológico que estaba viviendo el pueblo español. Debía ser una obra actual, en presente. Un film que era definido, en palabras de sus realizadores, como "la película del pueblo". Una obra que, por su carácter formal, dejaba que los españoles ilustrasen por sí mismos la situación social, política e histórica que estaban viviendo. De hecho, debía ser algo tan contemporáneo, tan reciente, que Cecilia Bartolomé hablaba de un film "vivo" la prensa apareció en el diario $A B C$.

El periodista responsable de la entrevista era consciente de que un documental de esas características podía encontrarse con alguna "dificultad" que los españoles no estaban muy a favor de "este tipo de encuestas"12. Calificarlo de encuesta venía a reforzar la idea de tomar el pulso al presente. Un presente que el propio periodista veía como "una faceta cinematográfica bastante arriesgada para una mujer" ${ }^{13}$. El film seguía teniendo, en ese momento, el nombre oficioso de Después de Franco... y se encontraba a mitad de un rodaje que había comenzado en abril de 1979 y que no terminaría hasta finales de 1980.

Dos meses después de esa entrevista, en noviembre, y a tenor de "los resultados de los rodajes previstos y en su mayor parte ya realizados"14, la película volvía a

\footnotetext{
8 Galindo, C. "Cecilia Bartolomé: película testimonio sobre el cambio sociológico español”. $A B C, 30$ de septiembre de 1979, p. 60.

9 Ibídem.

${ }^{10}$ Ibídem.

${ }^{11}$ Ibídem.

${ }^{12}$ Ibídem.

${ }^{13}$ Ibídem.

${ }^{14}$ Anónimo. "No se os puede dejar solos, el próximo filme de Cecilia Bartolomé”. La Vanguardia, 21 de noviembre, 1979, p. 53.
} 
aparecer en la prensa para "desformalizar el título primero"15, el que hacía referencia a Franco, por el de No se os puede dejar solos. Como ya hemos escrito, el rodaje se alargó y, en consecuencia, también el metraje; así que cuando se presentó para su calificación al Ministerio de Cultura -febrero de 1981-, mantuvo el nombre que acabamos de citar pero incorporó el de Atado y bien atado. Ambos apelativos se escondían bajo un título que englobaba a los dos: Después de... Habían eliminado el nombre del dictador pero seguían utilizado dos expresiones relacionadas con su figura que inevitablemente unían el film con su legado político. El contenido propuesto era tan actual que enviarlo para su calificación en una fecha tan señalada les dio problemas.

Las primeras revelaciones en la prensa acerca de esos problemas administrativos vendrían durante su presentación oficial. En el festival de San Sebastián, en septiembre de 1981, la revista oficial del certamen expuso, antes de que el documental hubiese llegado al gran público, es decir, a las salas comerciales, las dificultades que la cinta de los hermanos Bartolomé estaba teniendo con el Ministerio de Cultura para poder ser calificada y exhibida con normalidad. En sus páginas se describía la posibilidad de que la cinta fuese secuestrada por incitar a la violencia ${ }^{16}$. Tras ser proyectada en San Sebastián el film viajó a Barcelona en octubre, donde continuó la información acerca de su situación burocrática. La Setmana de Cinema de Barcelona la seleccionó y programó para ser exhibida el día 15 del citado mes ${ }^{17}$ y Cecilia Bartolomé dio una rueda de prensa que trascendió a los medios y en la que verbalizó los problemas que estaba teniendo con el Ministerio. La realizadora señaló "la incógnita [que circulaba] sobre su película a raíz de la denuncia del Ministerio de Cultura ante el Ministerio Fiscal por considerar, como ocurrió en el caso de El crimen de Cuenca, que puede ser objeto de delito" ${ }^{18}$. Lo era porque, como se sugería en La Vanguardia, Después de... era una "crónica contemporánea" 19 . Una película que, en palabras de la realizadora, solo pretendía "mostrar la realidad"20 de una forma objetiva. De hecho, la citada crónica sugirió que el film habría mostrado el golpe de estado si la primera copia estándar no hubiese aparecido en marzo de ese año. Su situación era una incógnita porque no se podía censurar su estreno -oficialmente-, ni secuestrarla, sin que se hubiese estrenado primero.

Estas dudas y rumores se transformaron en noticia en mayo de 1982 cuando se hizo pública la opinión que el Ministerio de Cultura tenía sobre Después de...; un hecho que venía a romper el silencio y el stand by en el que había entrado el film después de su presentación en los certámenes antes mencionados. La crónica que apareció en El País es la más completa ${ }^{21}$. La junta que debía valorar la película, siempre según esta información, estaba compuesta por un importante grupo de ex-

\footnotetext{
${ }^{15}$ Ibídem.

${ }^{16}$ Anónimo. "Después de... (1 $1^{\mathrm{a}}$ y $2^{\mathrm{a}}$ parte) puede ser secuestrada". Festival, no 10,26 de septiembre de 1981, p. 15.

${ }^{17}$ Recalcamos aquí que en ambos festivales se proyectaron las dos partes de forma continuada y bajo el título de Después de..., nunca por separado.

${ }^{18}$ Anónimo. "Cecilia Bartolomé teme un secuestro de su película "Y después de...". El Periódico de Catalunya, 16 de octubre de 1981, p. 30.

${ }^{19}$ S.M. "Después de...", crónica contemporánea. La Vanguardia, 16 de octubre de 1981, p. 47.

${ }^{20}$ Ibídem.

${ }^{21}$ Bedoya, J. G. "Después de... documental sobre la Transición Española, ha sido desposeído de las subvenciones estatales". El País, 7 de mayo de 1985, p. 35.
} 
pertos -“los productores J. L. Tafur y José Sámano, los directores Miguel Picazo, Fernando Méndez-Leite y Serrano de Osma y el documentalista López Clemente"22_ que tras una sesión celebrada el 30 de abril de 1981, decidió definir a Después de... como una película que contenía una "agresividad política terrible" (Gómez Vaquero, 2012: 221) que podía incurrir en delito ${ }^{23}$. Como consecuencia de esta decisión la obra no pudo obtener la subvención y ser estrenada. Para Cecilia Bartolomé esta junta de valoración tomó por unanimidad una decisión que ella consideró muy grave porque, en sus propias palabras, el Ministerio les estaba imponiendo una censura económica más eficaz que "la vieja censura ideológica del franquismo"24. La directora utilizó la prensa para expresar un hecho que ella consideraba probado: la negativa a la subvención se excusaba en la crítica de la junta de valoración pero era una orden que venía de otros ámbitos administrativos ${ }^{25}$. El papel que jugaba el film empezaba a ser parte de ese presente que deseaba captar y los medios no veían otra cosa que un conflicto ideológico enraizado en los cambios políticos que España estaba viviendo. Esta idea se ve reforzada cuando en la propia crónica de Bedoya se afirma que la administración no va a tener en cuenta Después de... porque, simplemente, su metraje no es cine ${ }^{26}$.

Un año después, en febrero de 1983, el trato que había recibido el film fue subsanado por el Ministerio. El escándalo acerca de su calificación, que anteriormente había ocupado amplias informaciones al respecto, ahora aparecía en la prensa de manera escueta. Podemos escoger cualquiera de los breves que se publicaron y nos encontraremos con que, sencillamente, Después de... había obtenido, finalmente, la subvención que le correspondía a la misma vez que también se reconocía la suya a $E l$ proceso de Burgos (Imanol Uribe, 1979) ${ }^{27}$. Para la prensa, una película que hablaba en presente de los años 1979 y 1980 empezaba a considerarse pasado remoto debido a los cambios producidos tras el fallido golpe de estado de 1981 .

La situación política y administrativa que reflejaron los medios influyó sobremanera en las críticas cinematográficas que recibió una vez que se estrenó comercialmente en el Cinestudio Groucho el 7 de noviembre de 1983 así como en la percepción que los espectadores tuvieron al contemplarla. El horizonte de expectativas del film estaba profundamente marcado por el retraso de dos años en su estreno y por el

\footnotetext{
${ }^{22}$ Ibídem.

${ }^{23}$ Esta afirmación se puede leer en el expediente no $149-80 \mathrm{~N}$, presente en el Archivo General de la Administración Civil del Estado. El expediente está firmado con una rúbrica ilegible (Gómez Vaquero, 2012: 221).

${ }^{24}$ Bedoya, J. G. "Después de... documental sobre la Transición Española, ha sido desposeído de las subvenciones estatales". El País, 7 de mayo de 1985, p. 35.

${ }^{25}$ Estas adversidades administrativas y sociales pueden ser similares a las que vivió la película documental Rocío (Fernando Ruíz Vergara, 1980) (Alvarado, 2010); film que versaba sobre la romería del mismo nombre.

${ }^{26}$ La alusión concreta es la siguiente: "La película, realizada por profesionales conocidos del cine español, con un presupuesto de veinte millones de pesetas, participó en el último Festival de Cine de San Sebastián y recibió el premio a la mejor obra documental en la Semana Internacional de Cine de Barcelona. Sin embargo, el criterio de la Administración es que no se trata de cine”. Es decir que los hermanos Bartolomé no habían hecho una película, habían hecho otra cosa. Sin especificar exactamente el qué.

${ }^{27}$ Anónimo. "El proceso de Burgos" y "Después de...", rehabilitadas". ABC, 16 de febrero de 1983, p. 61.
} 
fuerte conflicto protagonizado con el Ministerio. Vamos a citar cinco críticas cinematográficas muy diferentes entre sí para construir un panorama adecuado.

Las tres primeras -El País, ABC y Egin- están enmarcadas en diarios de carácter generalista cuyos cronistas apelan a criterios impresionistas, sin una línea que exponga abiertamente los presupuesto teóricos y políticos desde el que abordar el hecho cinematográfico - más allá de la ideología del propio medio- y que, en función del firmante y sus gustos particulares, exponían aquellos hechos, adjetivos o elementos que consideraban relevantes.

Ángel Fernández-Santos escribía en El País que todo el metraje tenía no solo un aire clandestino y maldito, sino que enseñaba la "parte desconocida de la historia de [la] transición" 28 . Esta apreciación deseaba corroborar que la película, en su estreno comercial -1983-, para la prensa y para el público era eso: historia. Una película extemporánea no contemporánea (Elena \& Mestman, 2003: 92). Para nosotros, esta apreciación incidía en que para el público, la Transición se dio por finalizada en 1982, tanto política como cinematográficamente ${ }^{29}$, y el presente convulso que captaron los hermanos Bartolomé mostraba dos aspectos: la intransigencia del Estado hacia discursos que no comulgaban con la oficialidad y cómo esos discursos se debían construir en la marginalidad, tal y como deja ver Fernández-Santos al corroborar que Después de... se estrenó de forma clandestina en muchas ciudades españolas ${ }^{30}$.

La película ya era historia, pero era reciente. Además, en su metraje mostraba diferentes discursos y posicionamientos políticos; lo que suponía que en algunas críticas el análisis del film se centrase en los aspectos ideológicos defendidos por Cecilia y José J. Bartolomé. Dos ejemplos: Pedro Crespo, en las páginas de una crítica de $A B C$ que ha sido reseñada en muchas ocasiones, encontraba que el metraje estaba "intencionalmente" 31 dirigido a mostrar los elementos más hostiles de la sociedad porque, en definitiva, los hermanos Bartolomé entendían, ante el desencanto de la transición, que la única solución posible era la "revolución violenta"32. El texto de Crespo define en dos adjetivos los aspectos cinematográficos de la obra -“desiguales imágenes" y "cierta calidad formal" 33 -, mientras que dedica el resto de su crítica a hacer ver a sus lectores que se trata de un film izquierdista que sólo desea la revolución y que está históricamente desfasado. Frente a esta mirada, en consonancia con las expectativas de los lectores de Crespo, se situaba la del diario vasco Egin. Esta publicación expuso que estos hermanos alicantinos habían sido valientes porque un tema de esta actualidad política implicaba, en muchas ocasiones, una posición partidista.

\footnotetext{
${ }^{28}$ Fernández-Santos, Á. "Después de..." obra "maldita" del cine de la transición, se estrena con tres años de retraso. El País, 3 noviembre de 1983, p. 27.

${ }^{29}$ Nos acogemos aquí a la división cronológica que Pérez Perucha y Ponce utilizan en su trabajo sobre la el cine realizado durante la Transición y en la que advierten de la existencia de tres periodos: postfranquismo (1974-76), transición democrática (77-82) y democracia (1983 en adelante) (Pérez Perucha \& Ponce, 2011: 225).

${ }^{30}$ En este momento queremos recordar cómo los realizadores afirmaron -en la entrevista a $A B C$ firmada por Galindo en 1979- que el público al que entrevistaron se soltaba y hablaba con más franqueza cuando se le advertía que las grabaciones no eran para TVE si no para una película que, además, iba a verse en el extranjero.

${ }^{31}$ Crespo, P. "Después de..." de Cecilia y José Bartolomé". ABC, 10 de noviembre de 1983, p. 72.

${ }^{32}$ Ibídem.

${ }^{33}$ Ibídem.
} 
Siendo, incluso, osado entrar en un debate tan encendido. Mikel Insausti, que firmaba la crítica, seguía viendo el film en un tiempo presente, al contrario que Crespo, que la veía desfasada. No obstante, para Insausti, Después de... era un discurso, y una propuesta ideológica, fallida por culpa de las presiones administrativas que hemos descrito anteriormente y porque, aunque no lo expresa con estas palabras, la política de esa época era extremadamente compleja ${ }^{34}$.

Frente a estas tres opiniones, las dos restantes proceden de revistas especializadas en el ámbito cinematográfico pero con diferentes enfoques. La primera de ellas, firmada por Miguel Marías y perteneciente a la revista Casablanca, está enmarcada dentro de una corriente que se acerca al hecho cinematográfico de una forma "cin-

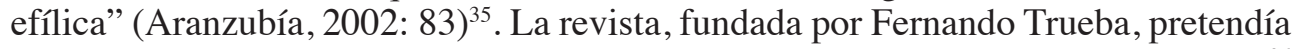
ser rigurosa "pero huyendo del ladrillismo doctiral, tan de moda en años recientes" y mostraba un interés especial por los monográficos sobre un realizador, al modo de la antigua Nuestro cine, dejando a un lado criterios ideológicos y teóricos precisos. Mientras que la segunda, publicada en Contracampo, estaba directamente vinculada con la renovación crítica que se había producido en España en los años setenta ${ }^{37}$ y con nuevos planteamientos teóricos que, estimulados por el estructuralismo, se concretaron en la semiótica fílmica de Metz y en el interés por la ideología en el cine -unida al lenguaje- que terminó con la influencia del marxismo sometido a la revisión de Louis Althusser (Nieto, 2009: 248). Por tanto, Contracampo imponía -tenía un editorial en cada número- unos presupuestos teóricos e ideológicos desde los que abordar el hecho cinematográfico ${ }^{38}$ buscando con ello un cierto análisis científico de la obra y una relación del film con el medio social que lo produce y consume (Nieto, 2009: 261).

Para Miguel Marías, la obra no solo era excepcional, sino que coincidiendo con las declaraciones de la directora que hemos escrito en la introducción, veía necesario registrar lo que ocurría día a día en España ante el peligro de que las informaciones que nos llegasen sobre este proceso político pudiesen ser confusas, profusas y contradictorias $^{39}$. Marías encontraba dentro de ella ese aire a cine clandestino, casi casero, heredero de aquellos colectivos de cine que salían a la calle únicamente acompañados de cámaras y magnetófonos ligeros para recoger la realidad inmediata. Era

\footnotetext{
${ }^{34}$ Insausti, M. "Después de..." 2a parte: "Atado y bien atado". El engaño al hombre de a pie". Egin, 25 septiembre de 1981, p. 19. A pesar de que la crítica es dura, años después la directora recordará la reseña de Egin como muy positiva. "Recuerdo que Egin me dedicó una doble crítica, una de carácter político e ideológico en la que discutían el planteamiento de la película porque no estaba a favor de ellos y otra de carácter artístico en la que la ponían muy bien y decían que éramos honestos, con lo cual conseguí salir bastante airosa" (Gregori, 2009: 960).

${ }^{35}$ Así es como define Casablanca Asier Aranzubía.

${ }^{36}$ Anónimo. "Aparece "Casablanca", nueva revista de cine”. El País, 8 de enero de 1981. Recuperado de http://elpais.com/diario/1981/01/08/cultura/347756411_850215.html. Palabras exactas de su fundador.

${ }^{37}$ Haciendo especial hincapié en los colectivos Marta Hernández y F. Creixels, fundados en 1973 y en 1974 respectivamente, así como en las revistas que precedían a Contracampo en este impulso por acercarse al cine desde diferentes metodologías: Filmguía y La mirada.

${ }^{38}$ Esto supuso la imposibilidad de ajustar la revista a una fecha determinada de salida y a la renuncia de contar el día a día de la realidad cinematográfica (Aranzubía, 2002: 79). Lo que choca directamente con Casablanca.

${ }^{39}$ Marías, M. “Crítica de Después de...”. Casablanca (Papeles de cine), nº 8, p. 86.
} 
una crítica que valoraba muy positivamente el trabajo fílmico de los hermanos Bartolomé e impulsaba a los jóvenes cineastas a copiarles. Situaba este trabajo dentro de una tradición documental que se remontaba a los años sesenta y a la aparición del cinema vérité. Un presente representado con técnicas aparecidas hacía veinte años y que reflejaba el atraso sufrido por el cine español debido a la dictadura. Plagada de emociones más que de un análisis riguroso, Marías impulsaba a los nuevos directores desde su más profunda cinefilia.

En su opuesto, el análisis que hacía Alberto Fernández Torres, que venía acompañado de una extensa entrevista a los realizadores ${ }^{40}$, Después de... debía "eliminar material informativamente poco relevante y perfectamente desechable"41 para conseguir, y centrándose en su montaje y su composición narrativa, que la cinta tuviese una verdadera "organización global" 42 que le diese sentido, porque, para el crítico, todo el metraje suponía una precipitación de acontecimientos. Torres entendía que la película debería construirse sobre una base mucho más consistente. Además, siguiendo a este crítico, el planteamiento formal elegido por los hermanos Bartolomé -que, como hemos dicho, ellos definieron como objetivo- no prometía hacer creer al espectador que la que hablaba era la realidad, sino el propio film. Esto implicaba negar la neutralidad buscada por los directores, pero también suponía unir Después de... con los problemas que el cine documental plantea acerca de la representación. Con los problemas que habíamos mencionado previamente acerca de los documentales que, siguiendo a Nichols, denominábamos interactivos.

Las críticas aparecidas en la prensa reflejaron la posición ideológica de cada medio, los planteamientos desde los que se acercaban al cine $\mathrm{y}$, al igual que el propio film, representaron el campo de batalla que era la realidad española durante la Transición. Salvo algunas coincidencias en las percepciones, como la marginalidad y los problemas burocráticos que arrastraba el film, la validez o no de su propuesta ideológica y formal variaba en función del firmante. Las diferentes perspectivas del presente histórico se imponían en el análisis de una película que se construía sobre su presente histórico. Esto también afectó a las interpretaciones de la obra dentro de los estudios fílmicos, es decir, a los significado(s) coetáneos del film.

\section{Después de... y la historiografía del cine español}

Terminábamos el epígrafe relativo a la prensa citando a la revista Contracampo y al texto que Alberto Fernández Torres escribió para ella en 1982. Dicha publicación fue objeto de una investigación publicada en el IX Congreso de la Asociación Española de Historiadores del Cine (AEHC) ${ }^{43}$ en la que Alejandro Montiel (Montiel, 2005:

\footnotetext{
${ }^{40}$ Dentro de los criterios que empleaba la revista esto le daba un especial interés al film (Aranzubía, 2002: 83). Además, hay que tener en cuenta que Contracampo tenía un compromiso especial con el cine español y la película de los hermanos Bartolomé abrió el n 29 de esa revista junto a Animación en la sala de espera (Manuel Coronado y Carlos Rodríguez, 1981) bajo un título que las definía como Cine español marginado y que reforzaba la idea planteada por Ángel Fernández-Santos. Hay que tener en cuenta que la crítica de Torres apareció antes del estreno en salas del film.

${ }^{41}$ Fernández Torres, A. Paisaje después de la batalla. Contracampo, no 29, p. 14.

${ }^{42}$ Ibídem.

${ }^{43}$ En ese mismo congreso también se incluyó el citado trabajo sobre Contracampo de Asier Aranzubía con la diferencia de que este último no citaba la obra de los hermanos Bartolomé.
} 
262), analizando los editoriales de Contracampo, encuentra que Después de..., además de recibir en su momento una atención extraordinaria dentro de esa revista a través de una extensa crítica y una entrevista, había sido considerada, con el paso del tiempo, primero como una obra confusa y fallida, después como un documento que advertía del riesgo de un golpe de estado para, por último, ser vista como un documental a reivindicar dentro de la Historia del Cine Español ${ }^{44}$.

Montiel cita un trabajo de Román Gubern, 1936-1939, la guerra de España en la pantalla: de la propaganda a la historia, publicado en 1986 y en donde, explícitamente, se comenta que esta película era "un fresco documental en dos partes [...] que advertía del riesgo del golpe de Estado que estallaría el 23 de febrero" (Gubern, 1986: 175) ${ }^{45}$. Esta afirmación está sustentada en las declaraciones que uno de los militares presentes en la segunda parte de la película realiza en el tramo final ${ }^{46} \mathrm{y}$, obviamente, en lo que ocurrió dentro del Congreso de los Diputados en febrero de 1981 y fuera de él después de ese mes. Si volvemos brevemente a algunas de las noticias que hemos comentado antes también encontraremos alusiones al golpe de estado. Por ejemplo, Ángel Fernández-Santos, en El País, presentaba el argumento de esta película como un "film maldito [...] sobre el ambiente que se respiraba en las calles de España antes del 23-F" ${ }^{\prime 47}$. Esta afirmación fue la que dominó inicialmente las reflexiones sobre el film. Lo podemos comprobar cuando en 1990, en su pase por Televisión Española, fue definida como un objeto del pasado apegado al fallido golpe militar. "Concluido en 1981, la intentona golpista rubricó su interés testimonial" 48 se afirmaba en la prensa el día de su pase por televisión ${ }^{49}$.

Esta muletilla -ser una advertencia del golpe de estado- es lo que, a nuestro juicio, se impuso inicialmente como una forma de definir el film; no como una obra confusa y fallida como afirma Montiel. Y es lo que, como hemos comprobado en las alusiones a la prensa que acabamos de citar, los medios y el público no especializado captaron en ella. Sin embargo, en los estudios que versaban sobre el cine

\footnotetext{
${ }^{44}$ Queremos señalar también que en el citado congreso (Lozano y Perucha, 2005), Después de... apareció, además de en el trabajo de Alejandro Montiel, en el texto que Laura Gómez Vaquero dedicó a Dolores (José Luis García Sánchez y Andrés Linares, 1981) como una película que se inscribe dentro de aquellas obras que construían una historia oral de su momento, de evidencia temporal de su presente (Gómez Vaquero, 2005 b).

${ }^{45}$ Esta obra fue una monografía publicada por la Filmoteca Española con motivo del cincuenta aniversario de la Guerra Civil. La reflexión que incluimos aquí está dentro de un apartado que habla sobre la representación de ese conflicto tras la dictadura. A pesar de esta inclusión, los hechos ocurridos entre 1936 y 1939 nunca se convierten en un punto central dentro de Después de....

${ }^{46}$ Las declaraciones están realizadas por el comandante Luis Otero, militar expulsado del ejército por pertenecer a la Unión Militar Democrática. Aunque las palabras son elocuentes, el mensaje que los directores transmiten a través del montaje paralelo realizado al final de la segunda parte -es un montaje sobre la situación del ejército tras el fin de la dictadura- es lo que alimenta el miedo a un posible golpe militar.

${ }^{47}$ Fernández-Santos, Á. "Después de..." obra "maldita" del cine de la transición, se estrena con tres años de retraso. El País, 3 noviembre de 1983, p. 27.

${ }^{48}$ Anónimo. Después de... La Vanguardia, 13 de mayo de 1990, p. 10.

${ }^{49}$ También somos conscientes que la película muestras una serie de advertencias al inicio de su metraje en las que, además de reafirmarse en la necesidad de su existencia, menciona la importancia del golpe de estado del 23 de febrero y en que lo que a continuación se va a mostrar no ha sido modificado por las nuevas circunstancias políticas surgidas después de ese hecho.
} 
español la definición sobre el trabajo de los hermanos Bartolomé estuvo ligada, y muy influencia, por el trabajo que Pérez Perucha y Vicente Ponce publicaron sobre el cine de la Transición ${ }^{50}$.

Estos autores firmaron el conocido texto Algunas instrucciones para evitar naufragios metodológicos y rastrear la Transición democrática en el cine español (Pérez Perucha \& Ponce, 2011) en donde dividieron las obras filmadas durante el postfranquismo y la Transición hacia la democracia en función de su contenido ideológico y las agruparon, de forma general, en dos corrientes: un cine de la reforma y un cine de la ruptura (Pérez Perucha \& Ponce, 2011: 232). Después de... era para ellos una película rupturista y estaba incluida dentro del apartado La república de los radicales en el que hablaban de "un grupo de realizadores y películas cuya posición no acababa de encajar en la lógica dominante de la Transición” (Pérez Perucha \& Ponce, 2011: 253) porque tenían propuestas ideológicas extremas y formalmente huían de los tradicionales modelos de representación ${ }^{51}$. No obstante, para los autores, si Después de... era radical era "ingenuamente" (Pérez Perucha y Ponce, 2011: 255) radical y la definían de tal forma que esa mirada coetánea antes expuesta -que era una mirada múltiple por cuanto múltiples eran las miradas sobre la compleja Transición- se traslado en un posicionamiento que derivaría en lo dicho por Montiel:

Es la articulación entre los segmentos, sustantiva en el dispositivo documental, la que derrumba en parte su radicalidad. Sin saber por dónde cortar, con una puesta en escena ciertamente original, sin mucha claridad narrativa respecto a qué era principal e imprescindible y qué secundario o prescindible, una desafortunada voz en off "hilo conductor" iluminándonos guía, innecesariamente, cual aseado lazarillo, por un texto cuya torrentera transicional no precisaba sumar lecturas añadidas (Perucha \& Ponce, 2011: 262).

En 1992, siguiendo la estela de Perucha y Ponce, en la publicación que Emilio Carlos García Fernández dedicó al cine español contemporáneo, este film aparecía dentro de una categoría -el documental y docudrama- que aborda problemas y temas que la sociedad conoce pero con los que tiene serios problemas para lidiar de forma directa (García Fernández, 1992: 82). Esta afirmación proponía que la película, por su contenido, no era cómoda para su visionado dentro de su contexto histórico, de su presente $^{52}$. De esta forma, tres años después, con la publicación en 1995 de la Historia del Cine Español de Cátedra (Gubern, Monterde, Pérez Perucha, Riambau \& Torreiro, 1995) venía incluida una valoración respecto al trabajo de Cecilia y José J. Bartolomé dentro de un apartado, firmado por Casimiro Torreiro, que hablaba sobre el cine español al final del franquismo y durante la transición, en el que Después de...

\footnotetext{
${ }^{50}$ Publicado en 1986, el mismo año que la obra de Román Gubern.

${ }^{51}$ Incluso eran todavía más marginales porque dentro de este espacio el film estaba incluido en el apartado Los otros, mal llamados “documentales”. (Pérez Perucha \& Ponce, 2011: 259).

${ }^{52}$ Perucha y Ponce afirmaban también que las películas de La república de los radicales eran "políticamente radicales por cuanto hunden sus propuestas en aquello que la sociedad civil reprime como indeseable y prefiere no decirlo" (Pérez Perucha \& Ponce, 2011: 254)
} 
era una crónica de urgencia de los días posteriores a la muerte de Franco "confusa y a la postre fallida" (Torreiro, 1995: 393).

Esta sentencia - rotunda y, repetimos, posterior a la vinculación con el golpe de estado- recortaba la riqueza de sentido que inicialmente tenía el film. La afirmación era válida tanto para su contenido como para su propuesta formal de "urgencia" (Torreiro, 1995: 393) y le otorgaba poca relevancia una vez que había pasado más de una década de su estreno. Las catalogaciones de Torreiro y García Fernández ejemplifican qué significaba Después de ... para la historiografía del cine español con vocación generalista: una película de tiempo presente, de poca significación para el futuro y con un sentido único y meridiano. Además, estos dos casos anunciaban la desaparición de este trabajo en posteriores obras que con un carácter general abordaron el cine español o que con un carácter parcial abordaron el cine de la Transición. Será obviada en la Antología crítica coordinada por Julio Pérez Perucha (Pérez Perucha, 1997) en favor de películas documentales que, entendemos, según su editor, debían ejemplificar mejor las vicisitudes de la transición -El desencanto, El asesino de Pedralbes, La vieja memoria y Cada ver es...-, no apareció en 1989 en el influyente trabajo que John Hopewell escribió sobre el cine realizado tras la muerte de Franco (John Hopewell, 1989), ni tampoco en obras de Caparrós Lera como El cine español de la democracia (Caparrós, 1992), escrita en 1992, o su Historia del Cine Español publicada en el año 2007 (Caparrós, 2007), ni en el acercamiento que de esos años realizó Monterde (Monterde, 1993). Por su puesto, su abandono seguiría siendo efectivo incluso en obras con una vocación monumental como la Guía del cine español de Carlos Aguilar, que también vio la luz en 2007.

Todos estos trabajos que acabamos de citar describen una selección pequeña de un espacio muy amplio y son, como toda historia general, el reflejo de las decisiones de un autor que busca dar una idea de conjunto de su objeto de estudio -bien sea todo el cine español o un periodo concreto-. Además, son obras que responden a los progresivos cambios que la historiografía del cine en España estaba viviendo. Si en los ochenta hubo un incremento notable de trabajos que abordaron el cine español y que se encontraron con "un territorio cuasi ignoto y semivirgen" (Zumalde, 2005: 445) en el que casi todo estaba por ser investigado ${ }^{53}$; en los noventa llegaron las vacas gordas y los estudios sobre la filmografía patria adquirieron "trazas de aluvión" (Zumalde, 2005: 455) ${ }^{54}$. Desde ese momento, las investigaciones sobre el cine español se diversificaron y empezó a haber un interés especial por el cine documental -los textos que abordaban la no ficción-, los estudios sobre la mujer o incluso nuevas perspectivas desde las que abordar el estudio del cine español durante la Transición ${ }^{55}$.

Es en este contexto donde la afirmación de Alejandro Montiel sobre su reivindicación cobra sentido. En 1999, Manuel Trenzado Romero, en su trabajo sobre el cine español durante la Transición, razonaba que Después de... era "un exponente del certificado de defunción de un cine documental que, si bien minoritario, no

\footnotetext{
${ }_{53}$ Destacando el desarrollo de los estudios sobre cines autonómicos o regionales.

${ }^{54}$ Donde aparecieron historias generales del cine español o historias por periodos, numerosas monografías sobre cineastas y otros oficios del cine y se empezaron a diversificar los estudios fílmicos en España.

${ }^{55}$ De forma general hubo una importante evolución desde el desprecio por una gran parte del cine patrio hasta la asunción de que el hecho cinematográfico español es simplemente particular y concreto y se deben investigar sus procesos, formas, tradiciones, etc. y no su bondad o maldad (Castro de Paz, 2002).
} 
dejaba de resultar molesto y que la propia legislación proteccionista de UCD acabó por cercenar" (Trenzado Romero, 1999: 270). Trenzado Romero ponía en evidencia dos hechos que aparecieron en la prensa que antes hemos analizado: su temática era un inconveniente y, además, por ser un documental, había sido burocráticamente marginado. Además, le otorgaba, por primera vez, una importancia histórica, la de certificado de defunción de su género, que la hacía imagen de su presente, no sólo testigo de su presente ${ }^{56}$. Dos años después, la reivindicación más clara y meridiana se hacía efectiva en el texto que Marta Selva i Masoliver le dedicaba en Imagen, memoria y fascinación. Notas sobre el documental en España (Català, Cerdán \& Torreiro, 2001). Esta obra podía ser considerada como una -primera, rigurosa y oficiosa- historia general del cine documental en España y en ella se dedicaba al film de los hermanos Bartolomé una importancia relevante. Las palabras que utiliza Selva i Masoliver son tan elocuentes que no merecen ser parafraseadas:

No vamos como país, sobradas y sobrados de documentos que como éste o similares, ofrezcan una aproximación al pasado desde este ejercicio de la creación documental, tan rico en matices e información, como para permitirnos el lujo de tener guardado, lleno de polvo y sólo disponible para eruditos este Después de... Se trata de un material que nos recuerda que las cosas tienen consecuencias, que lo que desde muchos sectores se reivindica en términos de mejoras laborales, sociales, educativas y culturales tiene una tradición que el aquí y ahora televisivo deja en suspensión ahistórica (Masoliver, 2001: 276).

En este sentido, la apreciación de Masoliver coincidió en el tiempo con el trabajo que Josetxo Cerdán y Marina Díaz López, El encanto de la lógica (Cerdán \& Díaz López, 2001), le dedicaron a Cecilia Bartolomé y a toda su obra. En este libro se incluía un análisis muy extenso que alababa el film de forma considerable (Fernández Colorado, 2001), así como una apreciación que intentaba resumir su desaparición -en conjunto, el de todo el trabajo de Cecilia Bartolomé- en las obras de carácter general que antes citábamos: "el hecho de que Cecilia Bartolomé no aparezca en recientes antologías o diccionarios sobre cine español nos hace pensar en el funcionamiento de una censura psíquica-política en la construcción 'oficial' de la historia del cine español" (Parrondo, 2001: 33) ${ }^{57}$. Nuevos planteamientos estaban llegando para el trabajo de los hermanos Bartolomé, y para la historiografía del cine español, y la reivindicación se convirtió en tendencia.

Lo que plantearon los realizadores de Después de... empezó a ser tratado como un documento imprescindible para conocer la historia a pie de calle de la Transición. El film recogía, de esta forma, el legado histórico de todo un periodo político, no solo de sus años finales (79-82), y su carácter de crónica actual se transformaba en efigie de un pasado cercano. En el año 2004, en el trabajo sobre el cine español

\footnotetext{
${ }^{56}$ Trenzado Romero también afirmaba que era "probablemente [...] el mejor documental sobre la Transición política realizado jamás" (Trenzado Romero, 1999: 319).

${ }^{57}$ Esta idea también viene dada por que la directora siempre ha defendido su posición feminista.
} 
de la transición escrito por Hernández Ruíz y Pérez Rubio, Después de... ya era un "testigo privilegiado del presente [y por tanto] un documento [...] en primer grado” (Hernández Ruíz \& Pérez Rubio, 2004: 121). Las bases de esta recuperación se sustentaban en su importancia como expositor de un proceso político a pesar de que Hernández Ruíz y Pérez Rubio seguían considerando que la película tenía un didactismo, fundamentalmente a través de su voz en off, que lastraba todo el film ${ }^{58}$.

En el año 2005, Josetxo Cerdán tampoco se olvidaría de ella en su texto sobre el cine documental de los últimos veinte años -desde finales de los ochenta hasta inicios del siglo XXI- y la incluirá, aunque brevemente, dentro de la misma categoría que Trenzado Romero. Es decir, en aquellas películas que se encontraron trabas legales importantes y que significaron el final, precipitado, de la presencia del cine documental en las salas. En este caso, Cerdán también hacía una apreciación, sin matizar, que incluía a Después de... dentro de una "raigambre vanguardista (tanto en sentido político como artístico)" (Cerdán, 2005: 350) ${ }^{59}$. Dándole un valor cinematográfico, artístico si se prefiere llamar así, y negando las lagunas que habían visto Hernández Ruíz y Pérez Rubio en la obra, y que, incluso, ya apuntó Fernández Torres en aquella crítica aparecida en Contracampo antes de su estreno comercial.

Mientras que en el trabajo más extenso sobre el documental de la Transición española, Las voces del cambio ${ }^{60}$, Laura Gómez Vaquero hace hincapié en un juicio similar al que hizo Miguel Marías al "establecer una línea de continuidad entre ese cine militante de principio de la década de los setenta" (Gómez Vaquero, 2012: 222) y el trabajo de los Bartolomé o al de Fernández Torres cuando afirma que su "montaje [es] enormemente connotativo" (Gómez Vaquero, 2012: 223). Una sensación, esta última, que se recrudece, según su autora, ante la grave actitud que los realizadores mostraban con los entrevistados. Esta postura implicaba, siguiendo a Gómez Vaquero, conducir sus declaraciones con el objetivo de mostrar su desencanto ${ }^{61}$. Haciendo que los parlamentos no fuesen espontáneos sino intencionalmente espontáneos ${ }^{62}$.

De esta manera, y para reafirmar el proceso de actualización del filme, nos encontramos con que en el año 2014 aparecieron dos artículos, en diferentes revistas de investigación, resaltando el trabajo de los hermanos Bartolomé. Uno de ellos recogía

\footnotetext{
${ }^{58}$ Estos autores mantenían lo dicho por Perucha y Ponce. Es decir, seguían dividiendo los films en función de su ideología y mantenían una posición peyorativa acerca del montaje de Después.... pero le sumaban la importancia como documento que antes no existía.

59 También la tiene en una consideración positiva en su texto sobre el documental en la España del tardocapitalismo publicado tres años después (Cerdán, 2008: 4-19).

${ }^{60}$ Este trabajo está basado en la tesis doctoral de la autora, ¡La calle es nuestra! El documental de entrevista durante la transición (1975-1981) (Gómez Vaquero, 2011).

${ }^{61}$ Un desencanto que, dicho sea de paso, era un estado de ánimo común que se puede rastrear en un gran número de los documentales que se hicieron durante la transición.

${ }^{62}$ En este sentido, Laura Gómez Vaquero, expresaba dos años antes lo siguiente: "Después de ... no sería estrenada en las salas hasta noviembre de 1983 por considerarse un film radical que mostraba una sociedad dividida y hasta enfrentada, poniendo en entredicho la consecución de una transición que ya en sus últimos años se publicitaba como modélica" (Gómez Vaquero, 2010) en un texto sobre la libertad de expresión en el documental español después de la Transición. Una reflexión que se suma y completa a otra realizada por la misma autora, en la que incluía a Después de ... como "el ejemplo más evidente del proceso de democratización que estaba sufriendo el país" (Gómez Vaquero 2005 a: 22) porque en ella aparecían personas anónimas que hasta ese momento no habían tenido la posibilidad de expresar sus opiniones.
} 
los aspectos cercanos al discurso político e histórico que encierra Después de..., es decir, a su relevancia como documento, mientras que el otro se centraba en cuestionar, fundamentalmente, su aparato cinematográfico -como un cine vinculado a la no ficción-. Elena Blázquez ahonda en su importancia como documento sociológico y por tanto suscribe la tesis de Masoliver, resaltando que su publicación está incluida dentro de una revista cuyo objeto de estudio no es el cine sino la historia (Blázquez, 2014). Mientras que Belén Puebla, que si tiene en cuenta el punto de vista estrictamente cinematográfico, afirma que Después de... se acerca mucho más a un reportaje televisivo que a un documental cinematográfico, siguiendo con la línea de valoración adversa hacia su propuesta formal (Puebla, 2014). No obstante, Puebla recuerda que la película es un testimonio de su tiempo, una película testimonio, un documento cargado ideológicamente pero necesario para reconstruir la memoria de la Transición.

\section{El tiempo presente}

Lo primero que queremos hacer es advertir la falta de consenso que genera esta película. En la historia de su paso por la prensa nos encontramos -dejando a un lado aquellas noticias que únicamente venían a constatar rasgos de sus trámites administrativos, de producción y de exhibición- con aquellos que le daban validez y apoyo a su apuesta cinematográfica, como Fernández-Santos, aquellos que no comulgaban con su propuesta ideológica, caso de Pedro Crespo, o los que defendían sus presupuestos formales, Miguel Marías como ejemplo. En el lado de los estudios fílmicos -más allá de que inicialmente haya sido obviada por algunos trabajos o desdeñada por otros- una vez que su metraje se ha recuperado para el discurso del cine español tampoco existe un acuerdo acerca de sus valores fílmicos pero si de sus valores como documento, de sus valores como fuente para el estudio de la Transición. Algo que solo puede otorgar el paso del tiempo.

Entendemos que la mirada coetánea del film es en realidad una serie de irreconciliables miradas que apostaron por descifrar el desafío ideológico y formal de los hermanos Bartolomé de forma múltiple. Sin embargo, esta división de opiniones se perdió a favor de un olvido y un desdén que, debido a los avances en los estudios sobre el cine español y a las nuevas líneas de investigación, se ha recuperado. No obstante, la recuperación y la vigencia del film no se quedan en el ámbito académico sino que viven dentro de un contexto que le otorga otro sentido.

Vamos a volver a una idea apuntada por Trenzado Romero para avanzar desde ahí hasta nuestro presente. Este autor definía Después de... como el acta de defunción del género documental. Esta afirmación, publicada en el año 1999, venía a ratificar lo que desde hacía quince años - contando desde esa fecha- venía ocurriendo en las salas de cine españolas. Desde los inicios de la Transición política, el público empezó a dar la espalda, de forma masiva, a las pantallas en las que se proyectaba cine español. Este hecho repercutió en el descenso de ingresos en taquilla y también afectó a otras producciones de carácter minoritario. En el caso del género documental, la ausencia de espectadores procedía también de ese rechazo al cine español pero también de la difícil competición que el cine de lo real empezaba a emprender con la televisión y de la falta de protección hacia el documental que mostraron las sucesivas leyes del cine. Junto a estas circunstancias, el boom que vivió el documental durante 
la Transición, gracias a la recién estrenada libertad de expresión que permitió hablar de temas hasta entonces vetados, se fue apagando con el paso de los años. La fecha clave que marca el abismal descenso de producciones es 1981. Consultando los datos que ofrece el Ministerio de Cultura, en esa fecha se estrenaron 9 películas documentales. Desde ese momento, la pérdida empezó a ser irreparable: entre 1982 y 1989, siempre según datos oficiales, los españoles solamente pudieron ir a ver al cine 7 largometrajes documentales ${ }^{63}$. La afirmación de Trenzado Romero es acertada: Después de... intentó ser estrenada comercialmente en 1981 pero una serie de trabas se lo impidieron, anunciando la difícil situación que para el documental estaba por venir. Además, el film de los hermanos Bartolomé no fue únicamente imagen de la futura ausencia del documental, también anunciaba la defunción de la política en el cine documental español.

1981 es el punto de inflexión para el género documental pero también lo fue para la España de aquellos años. Como apuntaba Cecilia Bartolomé, el fallido golpe de estado afectó al comportamiento del pueblo español: "[este país] tan radicalizado, tan esperpéntico y tan cabreado, cambió [...]. Y entonces, toda la gente que había estado despotricando contra la Constitución [...], de repente pensó que era mejor quedarse con la que tenía" (Gregori, 2009: 961). Cecilia Bartolomé explicaba que el popularmente conocido como tejerazo conllevó un disciplinamiento social de las posturas políticas que hasta ese momento habían mantenido muchos ciudadanos. Estas posturas están, de hecho, claramente reflejadas en Después de...: gran efervescencia reivindicativa de los movimientos sociales -haciendo especial hincapié en los feministas-, los problemas derivados del terrorismo de ETA -que continuará hasta entrado el siglo XXI-, el aumento de poder de la izquierda gracias a las primeras elecciones democráticas, la enorme capacidad de movilización de los sindicatos en busca de derechos sociales y las posturas de la derecha más radicalizada y contraria a los cambios que se estaban produciendo.

La actuación de Tejero en el congreso y la victoria del PSOE un año después destensaron la cuerda y España empezó a mecerse en una prosperidad que tendrá uno de sus puntos álgidos en los años noventa. ¿Qué ocurrió al mismo tiempo con el cine documental? Lo que anticipábamos anteriormente: el género fue renaciendo con lentitud mientras se olvidaba de la política. Entre 1989 y 1999, el Ministerio apunta que los españoles pudieron acercarse al cine parar ver 17 largometrajes documentales. Estas películas tienen una serie de características comunes: interés por la historia del cine, por la experimentación forma o por la búsqueda de nuevos estilos vinculados al cine de lo real; pero ninguna de ellas muestra esa necesidad de aprehender la realidad política inmediata que se encuentra en Después de .. ${ }^{64}$ Cuando la política regrese a los largometrajes documentales lo hará esgrimiendo el concepto de memoria. De memoria histórica. Y no únicamente de la Transición sino, fundamentalmente, de

\footnotetext{
${ }^{63}$ Aunque esta afirmación tampoco sea del todo cierta, puesto que el Ministerio tiene evidencias de que esas obras fueron calificadas para su estreno pero únicamente arroja datos y fechas de su paso por salas de 2 de esas 7 películas.

${ }^{64}$ Ejemplos de las películas a las que hacemos referencia pueden ser Innisfree (José Luis Guerin, 1991), El sol del membrillo (Víctor Erice, 1992), Después de tantos años (Ricardo Franco, 1994), Ojalá, Val del Omar (Cristina Esteban, 1994), las obras musicales de Carlos Saura, Sexo oral (Chus Gutiérrez, 1994), Tren de sombras (José Luis Guerin, 1997) o Monos como Becky (Joaquín Jordá, 1999). Se pueden consultar los trabajos de Josetxo Cerdán $(2005,2008)$ para confirmar lo que aquí afirmamos.
} 
otro hecho transcendental del siglo XX español: la Guerra Civil y sus consecuencias. Este hecho ya había sido recuperado por el documental de los setenta, sin embargo, hubo que esperar hasta la aparición de una película como Asaltar los cielos (Javier Rioyo y José Luis López Linares, 1996), para que la política volviese a dar el salto al cine documental. Este interés recogía un movimiento que ya había empezado a aparecer en la televisión, a través de las películas promovidas por Dolors Genovès para TV3 o de documentales como Granado y Delgado. Un crimen legal (Lala Gomà y Xavier Montanyà, 1996), pero que tardaría en entrar con fuerza en el documental para la gran pantalla.

Será después de los noventa, coincidiendo con hechos como la creación de la Asociación para la Recuperación de la Memoria Histórica, fundada a finales del año 2000, o de éxitos populares como el de la novela Soldados de Salamina (Javier Cercas, 2001), cuando la sociedad española desarrolle un gran interés por estos temas. En ese instante, el cine documental español entra en un boom similar al vivido por el género durante la Transición hacia la democracia ${ }^{65}$ y redescubre el estilo cercano, a pie de calle, de Después de... Se interesa por la memoria histórica y por los sucesos políticos que afectan a la vida diaria de los españoles: desde el no a la guerra pasando por la huelga de Sintel, la resistencia minera o la gran oleada de inmigrantes que aterrizan persiguiendo la recién estrenada prosperidad española ${ }^{66}$. La recuperación historiográfica del trabajo de los hermanos Bartolomé que explicábamos en el apartado anterior viene impulsada por esta situación en la que se encuentra el cine de lo real. Un cine que busca en el pasado modelos similares a su hacer en el presente y que los pone en valor.

Después de... muestra una sociedad que pide un cambio, una sociedad en efervescencia y preocupada por su presente, por eso no sorprende que en la coyuntura política y económica actual, marcada por la Gran Recesión que se inició en el año 2008, y en donde el discurso oficial de la Transición está cambiando y aparecen también documentales que cuestionan no solo el pasado lejano guerracivilista sino la creación de la democracia actual; la obra de los hermanos Bartolomé se esté volviendo a proyectar en algunos festivales ${ }^{67}$ y está viajando por primera vez a otros países ${ }^{68}$ como la imagen de una lucha por el presente.

En su contexto, Después de... participó en la construcción de lo que debía ser un cine en democracia. En un proceso que Carlo Lizzani definía de la siguiente manera:

\footnotetext{
${ }^{65}$ Los motivos de este nuevo boom son muy diversos: la nueva formación en cine documental que ofrecen algunas universidades catalanas, el abaratamiento y la ligereza de los equipos de filmación, la aparición del digital, el desarrollo de internet como un modelo en el distribuir estos contenidos que pueden ser más marginales, el importante magisterio de realizadores como Guerin o Jordá, la influencia de programas de televisión que tienen a la realidad como materia de trabajos, etc.

${ }^{66}$ Estos temas no serán los únicos que desarrolle el cine documental español una vez entrado el siglo XXI pero es uno de los más relevantes teniendo en cuenta la desaparición previa del interés por la política. Dicho esto, es necesario tener en cuenta que a día de hoy el cine de lo real en España es un cine plural donde hay apuestas formales y temáticas de todo tipo.

${ }^{67}$ Destacamos su proyección en el Festival Documenta Madrid que tuvo lugar en el año 2013 en donde se hacía una retrospectiva sobre el cine documental realizado en España durante la Transición.

${ }^{68}$ Se proyectó en Egipto en el marco de lo que popularmente se conoció como primavera árabe como un film que mostraba la lucha por construir un estado nuevo y democrático y como esa lucha se vio truncada a favor de una transición pactada pero insuficiente.
} 
"El cine español de 1978, al igual que el italiano de 1945, sale del fascismo y ha de reconstruirse en el sentido más total del término" (Caparrós, 1981: 34). Y la propuesta para hacerlo fue, efectivamente, la de la urgencia, la de la inmediatez. La de utilizar una estrategia discursiva que permitiese una identificación con lo real y, a la misma vez, una influencia lo más grande posible dentro de lo real. Es decir, un documental. Después de... asimiló la práctica de aquellos films que durante la Guerra Civil se filmaban y editaban con la premura y las necesidades que exige un tiempo bélico -crear mensajes para influir en el presente- y apostó por una pluralidad de voces que chocaba de frente con lo expuesto a través del aparato de producción de mensajes del franquismo: NO-DO.

Los hermanos Bartolomé desarrollaron esta técnica en contra, afirmaban, de unos medios de comunicación que no representaban el pulso del pueblo. ¿Cuál es la consecuencia formal de esta decisión? Entrevistas a pie de calle, entrevistas preparadas, mítines, manifestaciones, plenos en un ayuntamiento, debates en la calle,... que implicaban la corrección continua del encuadre, la inclusión de secuencias con movimientos, en ocasiones, poco estables, la pérdida de luz por estar en determinadas concentraciones que exigirían, si se hubiese podido, una mejor preparación lumínica o la necesaria inclusión de rótulos y de una voz en off que diesen orden al caos que podía suponer presentar esas imágenes sin un orden de continuidad adecuado. En nuestro presente, Después de... es una reafirmación del trabajo documental que algunos realizadores españoles del siglo XXI están llevando a cabo. La elección de una estética aparentemente irrelevante es consecuencia de una decisión ideológica y también de un posicionamiento formal previamente meditado ${ }^{69}$.

\section{Conclusiones}

Llegados a este punto podemos responder a las preguntas que nos hacíamos en el segundo apartado de este trabajo y en las que veníamos a cuestionarnos dos elementos: el significado de Después de... para nuestro tiempo presente y la supuesta vigencia de la obra de los hermanos Bartolomé pese haberse compuesto como un film enraizado en su presente histórico.

La primera de ellas está irremediablemente vinculada con el apartado dedicado a la relación del film con los estudios fílmicos, puesto que es recuperada con profusión debido a las nuevas derivas historiográficas sobre el cine español, y con el contexto presente que presentábamos en el apartado inmediatamente anterior, puesto que el aumento del interés por el cine de no ficción en España ha llevado a explorar viejos modelos documentales entre los que se encuentra Después de...Por eso, entendemos que este film tiene un doble significado para nuestro tiempo. En primer lugar, el de ser una forma discursiva a reivindicar por los cineastas del presente, y por tanto a imitar, porque los cambios políticos y sociales que vive en la actualidad la sociedad

\footnotetext{
${ }^{69}$ Podríamos citar algunas obras que se enmarcarían en esta tesitura de buscar el presente e intentar cambiarlo a través de su trabajo, al mismo tiempo que exponen un claro posicionamiento ideológico y una apuesta formal de inmediatez y de servicio a una causa: Libre te quiero (Basilio Martín Patino, 2012), El efecto Iguazú (Pere Joan Ventura, 2003), Ciutat Morta (Xavier Artigas y Xapo Ortega, 2014), 200 km (Discusión 14, 2003), Ich bin Enric Marco (Lucas Vermal y Santiago Fillol, 2009), La plaza (Adriano Morán, 2012) o La pelota vasca. La piel contra la piedra (Julio Medem, 2003).
} 
española invitan a realizar ejercicios fílmicos que pueden asemejarse a los realizados durante la Transición. Y, en segundo lugar, a ser un ejemplo de un cine español históricamente marginado que únicamente encuentra su significado en la Historia del Cine Español cuando la apertura de miradas sobre este hecho fílmico permiten ver un pasado más complejo -y más completo- de nuestro cine.

En lo relativo a su vigencia habría que hacer alusión directa a su mirada coetánea, es decir, a la mirada que las diferentes voces de la Transición dieron a un film que hablaba sobre esas voces, y al hecho de que actualmente se esté cuestionando el discurso oficial ligado a ese proceso histórico. En otras palabras, su vigencia estriba en el cuestionamiento que Después de... realizó del cambio político que estaba viviendo porque a día de hoy se está poniendo en duda tanto la transición hacia la democracia como, y por consecuencia, las bases de nuestro mundo actual.

Después de... se ha transformado y ha dejado de ser una historia del presente para ser una historia de lo que nos es presente. Es decir, de aquello que, independientemente de la distancia que nos separe, nos afecta directamente y sobre cuyas decisiones dependerá nuestro futuro.

\section{Referencias bibliográficas}

ALVARADO,A. (2010). Maldita Rocío: la película más prohibida, la que algunos quisieran ignorar. Blocs\&Docs. Recuperado de http://www.blogsandocs.com/?p=640 ARANZUBÍA, A. (2002). Contracampo y el cine español. Boletín Hispánico Helvético, $0,75-98$.

BLÁZQUEZ, E. (2014). Después de... una historia de la Transición. El futuro del pasado, $5,137-150$.

CAPARROS, J. M. (1992). El cine español de la democracia. De la muerte de Franco al "cambio" socialista (1975-1989). Barcelona: Anthropos.

CAPARRÓS, J. M. (2007). Historia del cine español. Madrid: T\&B.

CAPARRÓS, J. M. (1981). Travelling por el cine contemporáneo. Barcelona: Rialp.

CASTRO DE PAZ, J. L. (2002). Work un progress. Algunas notas sobre una década de historiografía y teoría cinematográficas en España. Secuencias, 16, 24-32.

CATALÀ, J. M., CERDÁN, J., y TORREIRO, C. (eds.) (2010). Imagen, memoria y fascinación. Notas sobre el documental en España. Madrid: Ocho y medio/ Festival de Cine Español de Málaga.

CATALÀ, J. M. (2010). El presente perpetuo. Mekas en el siglo XXI. En E. Cuevas (ed.), La casa abierta: el cine doméstico y sus reciclajes contemporáneos (pp. 301-346). Madrid: Ocho y medio/Ayuntamiento de Madrid.

CERDÁN, J. (2005). Documental y experimentalidad en España: crónica urgente de los últimos veinte años. En J. Cerdán, y C. Torreiro (eds.), Documental y Vanguardia (pp. 349-390). Madrid: Cátedra. 
CERDÁN, J., y DÍAZ LÓPEZ, M. (eds.) (2001). Cecilia Bartolomé: el encanto de la lógica. Barcelona: La Fàbrica de Cinema Alternatiu.

CERDÁN, J. (2008). El documental en la España del tardocapitalismo: muerte y resurrección.: Pausa, 6, 4-19.

CUEVAS, E. (2010). La casa abierta: el cine doméstico y sus reciclajes contemporáneos. Madrid: Ocho y medio/Ayuntamiento de Madrid.

ELENA, A., y MESTMAN, M. E. (2003). Para un observador lejano. El documental latinoamericano en España. En P. A. Paranagua (coord.), Cine documental en América latina (pp. 79-92). Madrid: Cátedra.

FERNÁNDEZ COLORADO, L. (2001). El retablo de la transición. Después de... (1981). En J. Cerdán, y M. Díaz (eds.), Cecilia Bartolomé: El encanto de la lógica (pp. 63-73). Barcelona: La Fàbrica de Cinema Alternatiu.

GARCÍA FERNÁNDEZ, E. C. (1992). El cine español contemporáneo. Barcelona: CILHE.

GÓMEZ VAQUERO, L. (2010). El documental español tras la dictadura: el difícil camino hacia la libertad de expresión. Blocs\&Docs. Recuperado de http://www. blogsandocs.com/?p=643

GÓMEZ VAQUERO, L. (2005 a). Hibridaciones e imposturas en el documental de la Transición. En M. L. Ortega (coord.), Nada es lo que parece. Falsos documentales, hibridaciones y mestizajes del documental en España (pp. 21-46). Madrid: Ocho y medio/Ayuntamiento de Madrid.

GÓMEZ VAQUERO, L. (2005 b). La entrevista en el cine documental de la Transición. Identidad y memoria en Dolores, de A. Linares y J. L. García Sánchez (1980). En A. Lozano Aguilar, y J. Pérez Perucha (coords.), El Cine Español durante la Transición democrática (1974-1983) (pp. 333-349). Madrid: Academia de las Artes y las Ciencias Cinematográficas de España/A.E.H.C.

GÓMEZ VAQUERO, L. (2011). ¡La calle es nuestra! el documental de entrevista durante la transición (1975-1981). Madrid: Universidad Autónoma de Madrid.

GÓMEZ VAQUERO, L. (2012). Las voces del cambio. La palabra en el documental durante la Transición en España. Madrid: Ayuntamiento de Madrid/Área de Gobierno de las Artes.

GREGORI, A. (2009). El cine español según sus directores. Madrid: Cátedra.

GUBERN, R. (1986). 1936-1939, la guerra de España en la pantalla: de la propaganda a la historia. Madrid: Filmoteca Española.

GUBERN, R., MONTERDE, J. E., PÉREZ PERUCHA, J., RIAMBAU, E., y TORREIRO, C. (2005). Historia del cine español. Madrid: Cátedra.

HERNÁNDEZ RUÍZ, J., y PÉREZ RUBIO, P. (2004). Voces en la niebla: el cine durante la transición española (1973- 1982). Ibérica: Madrid.

HERNÁNDEZ-SANTAOLALLA, V. (2010). De la Escuela de Constanza a la Teoría de la Recepción Cinematográfica. Un viaje de ida y vuelta. Frame, 6, 196-218.

HERRERA, J. (2001). Los estudios de recepción crítica en la historia del cine español. El caso de "Las Hurdes" de Buñuel. En L. Fernández Colorado, y P. CoutoCantero (coords.), La herida de las sombras. El cine español en los años 40 (pp. 399-404). Madrid: Academia de las Artes y las Ciencias Cinematográficas de España/A.E.H.C. 
HOPEWELL, J. (1989). El cine español después de Franco, 1973-1988. Madrid: Ediciones el arquero.

LOZANO, A., y PÉREZ PERUCHA, J. (coords.) (2005). El Cine Español durante la Transición democrática (1974-1983). Madrid: Academia de las Artes y las Ciencias Cinematográficas de España/A.E.H.C.

MONTERDE, J. E. (1993). Veinte años de cine español. Un cine bajo la paradoja 1973 - 1992. Barcelona: Paidós.

MONTIEL, A. (2005). Días inolvidables La recepción del cine español de la Transición en los editoriales de Contracampo (1979-1987). En A. Lozano Aguilar, y J. Pérez Perucha, (coords.), El Cine Español durante la Transición democrática (1974-1983) (pp. 257-274). Madrid: Academia de las Artes y las Ciencias Cinematográficas de España/A.E.H.C.

NICHOLS, B. (1997). La representación de la realidad. Cuestiones y conceptos sobre el documental. Madrid: Paidós.

NIETO, J. (2009). Cine en papel. Cultura y crítica cinematográfica en España (1939-1962). Valencia: Ediciones de la Filmoteca.

PARRONDO, E. (2001). Vámonos Bárbara, hacia la libertad. En J. Cerdán, y M. Díaz (eds.), Cecilia Bartolomé: El encanto de la lógica (pp. 33-42). Barcelona: La Fàbrica de Cinema Alternatiu.

PÉREZ PERUCHA, J. (1997). Antología crítica del cine español. Madrid: Cátedra. PÉREZ PERUCHA, J., y Ponce, V. (2011). Algunas instrucciones para evitar naufragios metodológicos y rastrear la Transición democrática en el cine español. En M. Palacio (coord.), El cine y la transición política en España (1975-1982) (pp. 223-268). Madrid: Biblioteca Nueva. Publicado originalmente en 1986.

PUEBLA, B. (2014). El documental en la Transición española, testimonio de su tiempo. Estudio de caso de Después de... (No se os puede dejar solos y Atado y bien atado).Revista de Cibercomunicación. Recuperado de http://revistadecibercomunicacion.com/index.php/cibercomunicacion/article/view/6/17

RIAMBAU, E. (2001). Vivir el presente, recuperar el pasado: El cine documental durante la transición (1973-1978). En J.M. Català, J. Cerdán, y C. Torreiro (eds.), Imagen, memoria y fascinación. Notas sobre el documental en España (pp. 125138). Madrid: Ocho y medio/ Festival de Cine Español de Málaga.

SELVA i MASOLIVER, M. (2001). La palabra necesaria. A propósito de Después de... (I y II parte En J.M. Català, J. Cerdán, y C. Torreiro (eds.), Imagen, memoria y fascinación. Notas sobre el documental en España (pp. 271-277). Madrid: Ocho y medio/ Festival de Cine Español de Málaga.

TORREIRO, C. (1995). Del tardofranquismo a la democracia (1969-1982). En R. Gubern, J.E. Monterde, J. Pérez Perucha, E. Riambau, y C. Torreiro, Historia del cine español (pp. 341-397). Madrid: Cátedra.

TRENZADO, M. (1999). Cultura de masas y cambio político: el cine español de la Transición. Madrid: Siglo XXI/ Centro de Investigaciones Sociológicas.

ZUMALDE, I. (2005). Asignatura pendiente. Pequeño breviario de la historiografía del cine español. En J.L Castro de Paz, J. Pérez Perucha, y S. Zunzunegui (eds.), La nueva memoria. Historia(s) del cine español (1939-2000) (pp. 420-481). A Coruña: Vía Láctea. 